\title{
Patients With Definite and Inconclusive Evidence of Reflux According to Lyon Consensus Display Similar Motility and Esophagogastric Junction Characteristics
}

\author{
Mentore Ribolsi, ${ }^{1 *}$ Edoardo Savarino, ${ }^{2}$ Benjamin Rogers, ${ }^{3}$ Arvind Rengarajan, ${ }^{3}$ Marco Della Coletta, ${ }^{2}$ Matteo Ghisa, \\ Michele Cicala, ${ }^{1}$ and C Prakash Gyawali ${ }^{3}$ \\ ${ }^{\prime}$ Unit of Gastroenterology, Campus Bio Medico University, Rome, Italy; ${ }^{2}$ Division of Gastroenterology, Department of Surgical, Oncological \\ and Gastroenterological Sciences, University of Padua, Padua, Italy; and ${ }^{3}$ Division of Gastroenterology, Department of Medicine, Washington \\ University School of Medicine, St. Louis, MO, USA
}

\section{Background/Aims}

The role of esophageal high-resolution manometry (HRM) within Lyon consensus phenotypes, especially patients with inconclusive gastroesophageal reflux disease (GERD) evidence, has not been fully investigated. In this multicenter, observational study we aim to compare HRM parameters in patients with GERD stratified according to the Lyon consensus.

\section{Methods}

Clinical and endoscopic data, HRM and multichannel intraluminal impedance-pH (MII-pH) studies performed off proton pump inhibitor therapy in patients with esophageal GERD symptoms were reviewed. Lyon consensus criteria identified pathological GERD, reflux hypersensitivity, functional heartburn, and inconclusive GERD. Patients, with inconclusive GERD were further subdivided into 2 groups based on total reflux numbers ( $\leq 80$ or $>80$ reflux episodes) during the MII-pH recording time.

\section{Results}

A total of 264 patients formed the study cohort. Pathological GERD and inconclusive GERD patients were associated with higher numbers of reflux episodes, lower mean nocturnal baseline impedance (MNBI) values, and a higher proportion of patients with pathologic MNBI compared to functional heartburn $(P<0.05$ for each comparison). On multivariate analysis, pathological GERD and inconclusive GERD patients, both with $\leq 80$ or $>80$ reflux episodes, were significantly associated with pathologic esophagogastric junction contractile integral values and with presence of hiatus hernia (type 2/3 esophagogastric junction). Patients with inconclusive GERD and $>80$ reflux episodes were significantly associated with fragmented peristalsis and ineffective esophageal motility whilst inconclusive GERD with $\leq 80$ reflux episodes were significantly associated with fragmented peristalsis.

\section{Conclusion}

Esophageal motor parameters on HRM are similar between pathologic and inconclusive GERD according to the Lyon consensus.

(J Neurogastroenterol Motil 2021;27:565-573)

Key Words

Esophagitis, peptic; Gastroesophageal reflux; Heartburn; Manometry

Received: July 13, 2020 Revised: November 13, 2020 Accepted: November 17, 2020

(a) This is an Open Access article distributed under the terms of the Creative Commons Attribution Non-Commercial License (http://creativecommons. org/licenses/by-nc/4.0) which permits unrestricted non-commercial use, distribution, and reproduction in any medium, provided the original work is properly cited.

${ }^{*}$ Correspondence: Mentore Ribolsi, MD Dipartimento di Malattie dell'Apparato Digerente, Università Campus Bio-Medico di Roma, Via Alvaro del Portillo 200 - 00128 Rome, Italy Tel: +39-06-225411, Fax: +39-06-225411638, E-mail: m.ribolsi@unicampus.it 


\section{Introduction}

Gastroesophageal reflux disease (GERD) represents one of the most common gastrointestinal disorders, with an increasing worldwide prevalence. ${ }^{1-4}$ The recent Lyon consensus delineates parameters on ambulatory reflux monitoring that categorically establish and rule out the presence of GERD. ${ }^{5}$ However, acid exposure time (AET) between $4 \%$ and $6 \%$ is defined as inconclusive GERD 5 where adjunctive investigative modalities and metrics, ${ }^{6-9}$ including endoscopy, histology, high-resolution manometry (HRM), and novel impedance metrics, may either confirm or refute the diagnosis of GERD. In particular, low mean nocturnal baseline impedance (MNBI) has been demonstrated to identify patients with borderline AET who respond to anti-reflux therapy. ${ }^{10}$

Metrics extracted from HRM may add confidence to a diagnosis of pathologic GERD when AET is borderline. ${ }^{11} \mathrm{HRM}$ evaluates pathophysiological factors relevant to $\mathrm{GERD}^{11,12}$ by providing detailed characterization of esophagogastric junction (EGJ) morphology, ${ }^{13}$ better understanding of the role of EGJ barrier function using the EGJ-contractile integral (EGJ-CI), ${ }^{14-16}$ and description of esophageal body motor function in the context of reflux clearance. ${ }^{17}$ Fragmented and failed swallows on HRM associate with abnormal reflux burden, ${ }^{18}$ and large breaks in esophageal peristaltic integrity, which are often identified in GERD-related chronic cough, ${ }^{19,20}$ associate with prolonged supine reflux clearance, higher AET, and erosive esophagitis. $^{21}$

Despite potential value in understanding GERD pathophysiology, the role of HRM within Lyon consensus phenotypes, especially in patients with inconclusive GERD evidence, has not been fully investigated. The present investigation is a multicenter, observational study aimed at evaluating and comparing HRM parameters in patients with GERD stratified according to the Lyon consensus.

\section{Materials and Methods}

\section{Patients}

In this retrospective observational study, consecutive adult patients (age $>18$ years) evaluated at 3 centers ( 2 in Italy and 1 in the United States) over a 2-year period (2017-2019) with esophageal HRM and ambulatory 24-hour multichannel intraluminal impedance-pH (MII-pH) monitoring were eligible for inclusion. Specific inclusion criteria were the presence of dominant esophageal symptoms (heartburn, regurgitation, and non-cardiac chest pain) ${ }^{22}$ unresponsive to acid suppressive therapy or requiring reflux testing to confirm the need for long-term proton pump inhibitor therapy as well as to document reflux presence prior to anti-reflux surgery in patients with persisting symptoms. Inclusion in this study also required ambulatory MII-pH studies, performed off acid-suppressive therapy (after at least 7 days pharmacological wash-out) ${ }^{23}$ and the presence of 10 supine water swallows for HRM analysis, performed with Chicago classification version $3.0\left(\mathrm{CC}\right.$ v3.0). ${ }^{24}$ Individuals with inadequate evaluation (equipment malfunction, poor study quality, and presence of artifacts) were not included. Moreover, patients with evidence of integrated relaxation pressure $>15 \mathrm{mmHg}$, connective tissue disease, history of neoplasia, and prior foregut surgery were excluded. The study protocol was approved by the institutional review board of the 3 University Centers, and each collaborating institution completed data sharing agreements for analysis of de-identified demographic, clinical, MIIpH, and HRM data (IRB 201607083).

\section{Symptom Assessment}

While esophageal symptoms (heartburn, regurgitation, and chest pain) were required for study inclusion, the presence of co-existing extra-esophageal symptoms (chronic cough, asthma, hoarseness, and globus) was also recorded. Esophageal symptom burden was assessed within the previous year on validated institutional questionnaires ${ }^{25-28}$ at each study site. While each center used its own set of questionnaires, the common element in the various questionnaires used was a $100 \mathrm{~mm}$ visual analog scale (VAS) where the patient was asked to make a mark on the $100 \mathrm{~mm}$ line as to where their symptoms were in the preceding 2 weeks $(0=$ no symptoms and $100=$ worst possible symptoms). VAS scales are a validated tool for assessment of change in perceptive symptoms and function within several domains, including gastrointestinal symptoms. ${ }^{29,30}$ VAS scales have been utilized in the assessment and follow-up of esophageal symptoms in the GERD context. ${ }^{10,31,32}$

\section{Esophageal High-resolution Manometry}

HRM was used to localize lower esophageal sphincter (LES) for optimal positioning of $\mathrm{pH}$-impedance catheters, performed on the same day as the MII-pH study. A catheter with 36 circumferential solid state pressure sensors, located at $1-\mathrm{cm}$ intervals (Medtronic, Duluth, GA, USA) was inserted, after an overnight fast, through an anesthetized nostril such that at least 3 distal pressure sensors were positioned in the stomach. Medications with potential to affect esophageal motility (metoclopramide, anticholinergics, calcium blockers, and opioids) were held whenever possible 
and for the safety of the patient. HRM studies were performed using ten $5 \mathrm{~mL}$ swallows of ambient temperature fluid at 30-second interval in a semi-recumbent position. ${ }^{33}$

HRM studied were evaluated according CC v3.0 criteria $^{24}$ : (1) intact swallow: distal contractile integral (DCI) $>450 \mathrm{mmHg} \cdot \mathrm{cm} \cdot \mathrm{sec}$; (2) fragmented swallow: DCI $>450 \mathrm{mmHg} \cdot \mathrm{cm} \cdot \mathrm{sec}$ with $>5 \mathrm{~cm}$ breaks; (3) weak swallow: DCI 100-450 mmHg.cm.sec; (4) failed swallow: DCI $<100 \mathrm{mmHg} \cdot \mathrm{cm} \cdot \mathrm{sec}$. CC v3.0 diagnoses consisted of the following: (1) fragmented peristalsis: $\geq 50 \%$ fragmented swallows; (2) ineffective esophageal motility (IEM): $\geq 50 \%$ of any combination of weak or failed swallows; and (3) absent contractility: $100 \%$ failed swallows.

EGJ-CI was measured using a DCI like tool, during a period of quiet rest over exactly 3 respiratory cycles, and divided by the duration of the respiratory cycles to make the metric independent of respiration. EGJ-CI was considered low when $<39.1 \mathrm{mmHg} \cdot \mathrm{cm}^{14,15}$ EGJ morphology was assessed considering the relationship between LES and crural diaphragm; type 1 when LES and crural diaphragm were superimposed, type 2 when separated $<3 \mathrm{~cm}$, and type 3 when separated $\geq 3 \mathrm{~cm}^{14}$

\section{4-Hour Multichannel Intraluminal Impedance-pH Monitoring}

MII-pH was recorded using a $2.3 \mathrm{~mm}$ diameter polyvinyl catheter assembly containing a series of impedance electrodes, each $4 \mathrm{~mm}$ in axial length, spaced at 2-cm intervals, and a distal antimony pH electrode (Sandhill Scientific Inc, Highlands Ranch, CO, USA). The $\mathrm{pH}$ electrodes were calibrated using $\mathrm{pH} 4.0$ and $\mathrm{pH}$ 7.0 buffer solutions before MII-pH monitoring. Following HRM, the catheter was passed through the anesthetized nostril, and positioned with the $\mathrm{pH}$ electrode $5 \mathrm{~cm}$ above the LES, and impedance electrodes at $3,5,7,9,15$, and $17 \mathrm{~cm}$ proximal to the LES. Event markers, corroborated with paper diaries, were used to record symptoms, meal times, and supine periods. AET was defined as pathological if the time $\mathrm{pH}<4$ exceeded $6 \%$ of the total recording time. ${ }^{4}$ Reflux-symptom association was assessed using symptom association probability (SAP) for all reflux episodes using previously described methodology. ${ }^{34-36}$ MNBI was calculated by measuring baseline impedance values at $3 \mathrm{~cm}$ above the LES, across stable nocturnal 10-minute periods (at or around 1 AM, 2 AM, and 3 AM). ${ }^{37}$ The values from the 3 time periods were averaged to yield the MNBI for each channel, and values < 2292 ohms defined abnormally low MNBI. ${ }^{37,38}$

\section{Patient Phenotypes}

According to MII-pH findings, patients with AET $>6 \%$ or with grade $\mathrm{C}-\mathrm{D}$ erosive esophagitis were defined as having pathological GERD. Patients with AET between $4 \%$ and $6 \%$ and with a negative SAP, were categorized into the inconclusive GERD group. Patients with AET $\leq 6 \%$ but with a positive SAP were diagnosed as reflux hypersensitivity $(\mathrm{RH})$. All patients with AET $\leq 4 \%$ and with a negative SAP were classified as functional heartburn $(\mathrm{FH})$. For comparison purposes, patients with $\mathrm{RH}$ and $\mathrm{FH}$ were retained in the study. HRM data were evaluated in all patients; those with inconclusive GERD were further subdivided into 2 groups according to the total number of reflux episodes during the MII-pH recording period ( $\leq 80$ or $>80$ reflux episodes).

\section{Statistical Methods}

Data are presented as median and interquartile range unless otherwise indicated. Comparisons between groups were assessed using the Fisher's exact test. Group means were compared using Mann-Whitney $U$ test, with Bonferroni correction for multiple comparisons when appropriate. Multivariate regression models were generated to evaluate the association between each GERD phenotype and HRM findings. Significance was achieved when the $P$-value was $<0.05$. SPSS 16.0 software (SPSS Inc, Chicago, IL, USA) was used to perform statistical analysis.

\section{Results}

\section{Study Population}

A total of 264 patients (165 female; mean age 47 years, range 19-73 years) with esophageal symptoms fulfilled inclusion criteria and formed the study cohort. In addition to esophageal symptoms in all patients, extra-esophageal symptoms were reported by approximately a third of patients (chronic cough $24 \%$, asthma 5\%, hoarseness $9 \%$, and globus $7 \%$ ). A total of 24 patients had erosive reflux disease (ERD) (15 grade A, 7 grade $\mathrm{B}$, and 2 grade $\mathrm{C}$ according to Los Angeles classification). Endoscopically identified hiatus hernia was detected in 51 out of 264 patients (19\%). 
Multichannel Intraluminal Impedance-pH Data in Patients With Pathological Gastroesophageal Reflux Disease, Inconclusive Gastroesophageal Reflux Disease, Reflux Hypersensitivity, and Functional Heartburn

Seventy-three patients were classified as having pathological GERD. There were 40 patients in the inconclusive GERD group, 59 had RH and 92 had FH. Patients with pathological GERD demonstrated a significantly higher total AET and AET during supine position compared to patients with inconclusive GERD.

Patients with pathological GERD and inconclusive GERD were characterized by a significantly higher median number of reflux episodes compared to patients with $\mathrm{FH}(P<0.05$ for each comparison; Table 1). Pathological GERD patients had a significantly higher median number of reflux episodes compared to $\mathrm{RH}$ patients $(P<0.05)$. Patients with pathological GERD and inconclusive GERD displayed a significantly lower $3 \mathrm{~cm}$ MNBI values compared to patients with $\mathrm{FH}$ (Table 1).
Pathological GERD and inconclusive GERD groups presented a significantly higher proportion of patients with abnormally low MNBI at $3 \mathrm{~cm}$ compared to FH group $(P<0.005$ for each comparison). Pathological GERD group was also characterized by a significantly higher proportion of patients with abnormal MNBI at $3 \mathrm{~cm}$ compared to RH group $(P=0.048)$ (Fig. 1A).

\section{High-resolution Manometry Data in Patients With Pathological Gastroesophageal Reflux Disease, Inconclusive Gastroesophageal Reflux Disease, Reflux Hypersensitivity, and Functional Heartburn}

HRM data were evaluated in patients with pathological GERD, inconclusive GERD, RH, and FH, the latter subdivided into 2 groups according to the total reflux number during the MII$\mathrm{pH}$ recording time ( $\leq 80$ or $>80$ reflux episodes). Patients with pathological GERD, inconclusive GERD $\leq 80$ reflux episodes, inconclusive GERD > 80 reflux episodes, and $\mathrm{RH}$ demonstrated significantly lower median basal LES pressure $(P=0.008, P=$ $0.040, P=0.040$, and $P=0.001$, respectively) and EGJ-CI

Table 1. Multichannel Intraluminal Impedance-pH Data in the Studied Groups

\begin{tabular}{lcccc}
\hline \multicolumn{1}{c}{ Variables } & $\begin{array}{c}\text { Pathological GERD } \\
(\mathrm{n}=73)\end{array}$ & $\begin{array}{c}\text { Inconclusive GERD } \\
(\mathrm{n}=40)\end{array}$ & $\begin{array}{c}\text { RH } \\
(\mathrm{n}=59)\end{array}$ & $\begin{array}{c}\text { FH } \\
(\mathrm{n}=92)\end{array}$ \\
\hline AET $(\%)$ & $10.0(8.3)^{\mathrm{a}}$ & $4.6(0.9)$ & $3.1(3.2)$ & $1.2(1.5)$ \\
AET supine $(\%)$ & $5.9(4.2)^{\mathrm{a}}$ & $1.8(0.4)$ & $1.6(0.9)$ & $0.7(0.5)$ \\
Reflux episodes & $72(52)^{\mathrm{b}}$ & $65(45)^{\mathrm{b}}$ & $47(34)$ & $46(34)$ \\
MNBI $(\Omega)$ & $1870(1651)^{\mathrm{c}}$ & $1657(1354)^{\mathrm{c}}$ & $2443(1450)$ & $2324(1615)$ \\
\hline
\end{tabular}

GERD, gastroesophageal reflux disease; RH, reflux hypersensitivity; FH, functional heartburn; AET, acid exposure time; MNBI, mean nocturnal baseline impedance. ${ }^{\mathrm{a}} \mathrm{P}<0.001$ vs inconclusive GERD, RH, and $\mathrm{FH} ;{ }^{\mathrm{b}} \mathrm{P}<0.05$ vs $\mathrm{FH} ;{ }^{\mathrm{c}} \mathrm{P}<0.05$ vs $\mathrm{FH}$.

Data are presented as median (interquartile range $[\mathrm{IQR}]$ ).
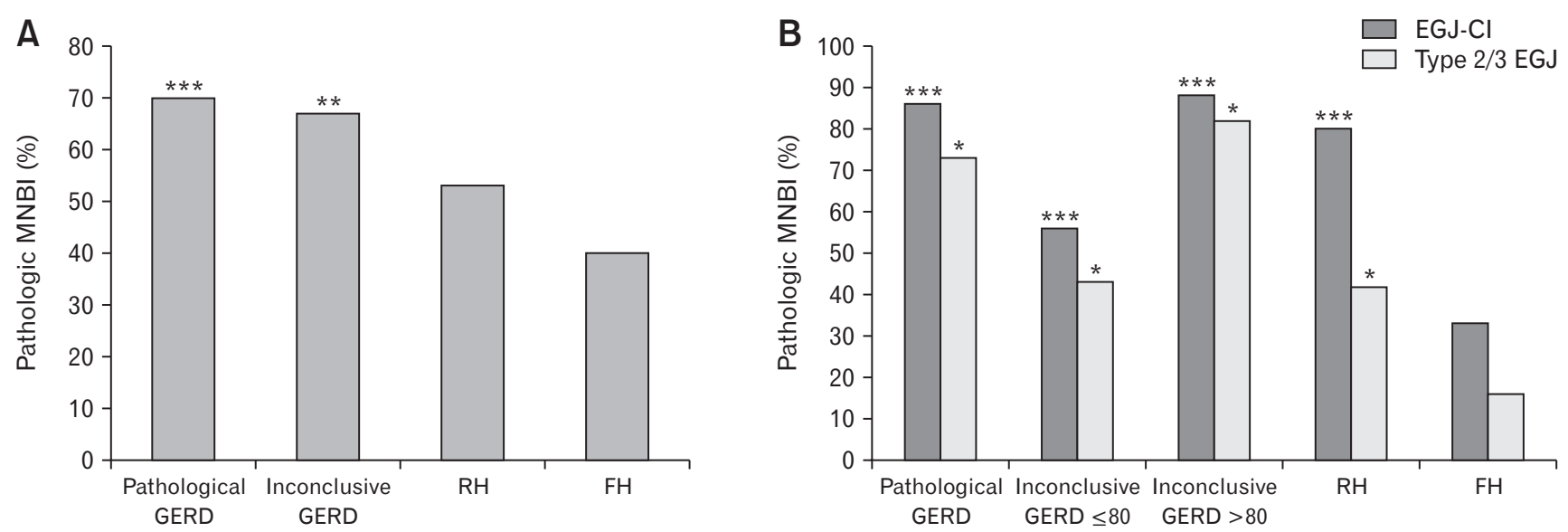

Figure 1. Proportion of patients with pathologic value of mean nocturnal baseline impedance (MNBI) at $3 \mathrm{~cm}(\mathrm{~A})$, and esophagogastric junction contractile integral (EGJ-CI) and type 2/3 esophagogastric junction (EGJ) (B) in the studied groups. RH, reflux hypersensitivity; FH, functional heartburn. ${ }^{*} \mathrm{P}<0.05$ vs $\mathrm{FH} ;{ }^{* *} \mathrm{P}<0.005$ vs $\mathrm{FH} ;{ }^{* *} \mathrm{P}<0.001$ vs $\mathrm{FH}$. 
Table 2. High-resolution Manometry Data in the Study Groups

\begin{tabular}{lccccc}
\hline \multicolumn{1}{c}{ Variables } & $\begin{array}{c}\text { Pathological GERD } \\
(\mathrm{n}=73)\end{array}$ & $\begin{array}{c}\text { Inconclusive } \\
\text { GERD } \leq 80 \\
(\mathrm{n}=23)\end{array}$ & $\begin{array}{c}\text { Inconclusive } \\
\text { GERD }>80 \\
(\mathrm{n}=17)\end{array}$ & $\begin{array}{c}\text { RH } \\
(\mathrm{n}=59)\end{array}$ & $\begin{array}{c}\text { FH } \\
(\mathrm{n}=92)\end{array}$ \\
\hline Basal LES pressure $(\mathrm{mmHg})$ & $19.2(13.7)^{\mathrm{a}}$ & $14.8(8.9)^{\mathrm{a}}$ & $14.2(15.3)^{\mathrm{a}}$ & $16.3(11.8)^{\mathrm{a}}$ & $25.7(13.9)$ \\
IRP $(\mathrm{mmHg})$ & $9.1(6.5)$ & $9.0(5)$ & $7.3(5.8)$ & $7.5(6.4)$ & $9.0(4.4)$ \\
EGJ-CI $(\mathrm{mmHg} \cdot \mathrm{cm})$ & $14.0(11.8)^{\mathrm{b}}$ & $22.9(30.1)^{\mathrm{b}}$ & $14.2(15.3)^{\mathrm{b}}$ & $17.0(17.7)^{\mathrm{b}}$ & $47.0(33.0)$ \\
DCI $(\mathrm{mmHg} \cdot \mathrm{cm} \cdot \mathrm{sec})$ & $555(1262)^{\mathrm{b}}$ & $1343(1887)$ & $1019(724)$ & $1812(1757)$ & $2105(2553)$ \\
\hline
\end{tabular}

GERD, gastroesophageal reflux disease; RH, reflux hypersensitivity; FH, functional heartburn; LES, lower esophageal sphincter; IRP, integrated relaxation pressure; EGJ-CI, esophagogastric junction contractile integral; DCI, distal contractile integral.

${ }^{a} P<0.05$ vs $\mathrm{FH} ;{ }^{\mathrm{b}} \mathrm{P}<0.01$ vs $\mathrm{FH}$.

Data are presented as median (interquartile range $[\mathrm{IQR}]$ ).

values $(P=0.006, P<0.001, P<0.001$, and $P=0.002$, respectively) compared to patients with $\mathrm{FH}$, while median integrated relaxation pressure values were comparable between the groups (Table 2)

Median DCI values were significantly lower in pathological GERD compared to FH patients $(P=0.001)$. Median DCI values in patients with inconclusive GERD $\leq 80$ reflux episodes, inconclusive GERD > 80 reflux episodes, and $\mathrm{RH}$ were lower compared to patients with $\mathrm{FH}$, although these differences were not different $(P=0.370, P=0.120$, and $P=0.070$, respectively; Table 2).

Pathological GERD, inconclusive GERD $\leq 80$ reflux episodes, inconclusive GERD > 80 reflux episodes, and RH groups had significantly higher proportions of patients with pathologic EGJ-CI or hiatus hernia (type $2 / 3 \mathrm{EGJ}$ ) compared to $\mathrm{FH}$ group $(P$ $<0.05$ for each comparison). Proportions of patients with pathologic EGJ-CI were similar among pathological GERD, inconclusive GERD > 80, and RH groups.

Pathological GERD and inconclusive GERD > 80 reflux episodes groups presented similar proportions of patients with type 2/3 EGJ, and a significantly higher proportion compared to inconclusive GERD $\leq 80$ reflux episodes and RH groups (Fig. 1B).

Inconclusive GERD > 80 reflux episodes and pathological GERD groups had significantly higher proportions of patients with hiatus hernia (type 2/3 EGJ) compared to $\mathrm{RH}$ group with AET between $4 \%$ and $6 \%(73 \%, 82 \%$, and $43 \%$, respectively; $P<0.01)$. Proportions of patients with pathologic EGJ-CI were similar between pathological GERD, inconclusive GERD > 80 reflux episodes, and RH with AET between $4 \%$ and $6 \%$ groups $(87 \%, 88 \%$, and $86 \%$, respectively). Proportions of patients with hypomotility features were higher in pathological GERD, inconclusive GERD $>80$ reflux episodes, and inconclusive GERD $\leq 80$ reflux episodes compared to RH with AET between $4 \%$ and $6 \%$ groups,
Table 3. Multivariate Analysis Results Comparing Esophagogastric Junction Metrics

\begin{tabular}{lcc}
\hline \multicolumn{1}{c}{ Patients } & $\begin{array}{c}\text { EGJ-CI } \\
\text { OR }(95 \% \mathrm{CI})\end{array}$ & $\begin{array}{c}\text { Type } 2 / 3 \mathrm{EGJ} \\
\text { OR }(95 \% \mathrm{CI})\end{array}$ \\
\hline Pathological GERD & $4.4(1.2-15.4)$ & $3.9(1.2-12.6)$ \\
Inconclusive GERD $\leq 80$ & $2.6(1.2-10.9)$ & $4.1(1.4-11.9)$ \\
Inconclusive GERD $>80$ & $6.5(2.7-15.4)$ & $7.2(3.0-16.2)$ \\
$\mathrm{RH}$ & $6.6(2.9-14.7)$ & $1.9(0.8-4.4)$ \\
\hline
\end{tabular}

EGJ-CI, esophagogastric junction contractile integral; GERD, gastroesophageal reflux disease; $\mathrm{RH}$, reflux hypersensitivity.

although these differences were not significant (49\%, 53\%, 40\%, and $29 \%$ respectively).

On multivariate analysis, in comparison to $\mathrm{FH}$ group, patients with pathological GERD and inconclusive GERD both with $\leq 80$ or $>80$ reflux episodes were significantly associated with pathologic EGJ-CI and hiatus hernia (type 2/3 EGJ). RH was significantly associated only with pathologic EGJ-CI (Table 3).

In the pathological GERD group, and inconclusive GERD groups with both $\leq 80$ and $>80$ reflux episodes, a significantly higher proportion of patients had evidence of esophageal body hypomotility features (absent peristalsis, fragmented peristalsis, and IEM) compared to the FH group $(P<0.005$ for each comparison) (Fig. 2). Pathological GERD and inconclusive GERD > 80 groups were also characterized by a significantly higher proportion of patients with esophageal body hypomotility compared to patients with $\mathrm{RH}(P<0.001$ and $P<0.005$, respectively $)$.

On multivariate analysis, in comparison to the $\mathrm{FH}$ group, pathological GERD was significantly associated with presence of absent peristalsis, fragmented peristalsis, and IEM. The inconclusive GERD group with $>80$ reflux episodes was significantly associated with presence of fragmented peristalsis and IEM. Inconclusive GERD with $\leq 80$ reflux episodes was significantly associ- 
ated with presence of fragmented peristalsis. Diagnosis of RH had no association with presence of IEM (Table 4).

\section{Discussion}

In this retrospective observational study, we compared HRM parameters in pathological GERD, RH, and $\mathrm{FH}$ as well as in patients with inconclusive evidence of GERD. Our results show, for the first time, that both pathologic GERD and inconclusive GERD phenotypes are characterized by similar EGJ metrics and morphology. Additionally, we report that both pathologic GERD and inconclusive GERD are associated with higher numbers of reflux episodes, lower mean MNBI values, and a higher proportion of patients with pathologic MNBI compared to $\mathrm{FH}$, with the only distinction between pathologic and inconclusive GERD being the AET value. We describe characteristics within inconclusive GERD that associate with abnormal HRM metrics, including $>80$ reflux episodes on MII-pH recordings. We conclude that a significant proportion of inconclusive GERD potentially represents pathologic GERD, and thus, the HRM findings supporting GERD patho-

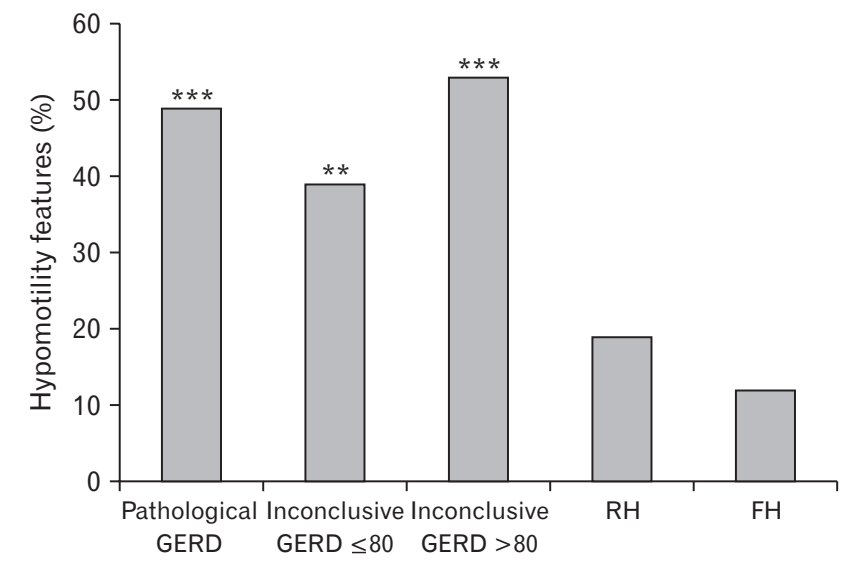

Figure 2. Proportion of patients with hypomotility features in the studied groups. $\mathrm{RH}$, reflux hypersensitivity; $\mathrm{FH}$, functional heartburn. ${ }^{* * *} P<0.001$ vs $\mathrm{FH} ;{ }^{* *} P<0.005$ vs FH. physiology add confidence in the presence of pathologic GERD. This is relevant, as patients with GERD undergoing catheter-based reflux monitoring typically undergo HRM studies for LES localization, and proton pump inhibitor non-responders undergo HRM studies are evaluated for achalasia, motor disorders, and behavioral syndromes; therefore HRM information is available to be analyzed and interpreted in these patients. Our findings support extracting HRM metrics relevant to GERD in this context, since these may provide additional GERD evidence as suggested by the Lyon consensus.

We selected a large cohort of patients with dominant esophageal symptoms being evaluated to document reflux evidence. Patients enrollment was symptom-based, to emulate the real world setting. Our findings are in agreement with a recent study by Rengarajan et $\mathrm{all}^{10}$ who showed that when low, MNBI is able to identify patients with pathologic and borderline AET who respond to antireflux therapy. Moreover, our results confirm that MNBI is able to increase the diagnostic yield of MII-pH monitoring in patients with reflux disease and negatively correlates with $\mathrm{AET}^{37-39}$ Our results concerning DCI are in keeping with previously published data, demonstrating that the vigor of the peristalsis during multiple rapid swallows, measured using DCI, inversely correlates with AET in patients with pathological GERD. ${ }^{40}$ This finding sustains the hypothesis, in keeping with previous studies, ${ }^{17-19}$ that lower peristaltic vigor correlates with higher reflux burden, as observed in patients with pathological GERD.

We demonstrate that pathologic GERD and inconclusive GERD phenotypes are characterized by similar EGJ metrics and morphology. Patients with $>80$ reflux episodes in the context of inconclusive GERD had similar proportions with abnormal EGJ morphology and pathologic EGJ-CI compared to pathologic GERD. Several published reports demonstrate that abnormal EGJ metrics and presence of hiatal hernia at HRM are associated with increased reflux burden. ${ }^{13-16}$ Similarly, low EGJ-CI is associated with abnormal total and supine acid burden, ${ }^{14}$ as well as a higher probability of positive MII-pH monitoring compared to normal

Table 4. Multivariate Analysis Results Comparing Esophageal Body Motor Function

\begin{tabular}{lccc}
\multicolumn{1}{c}{ Patients } & $\begin{array}{c}\text { Absent peristalsis } \\
\text { OR (95\% CI) }\end{array}$ & $\begin{array}{c}\text { Fragmented peristalsis } \\
\text { OR (95\% CI) }\end{array}$ & $\begin{array}{c}\text { IEM } \\
\text { OR (95\% CI) }\end{array}$ \\
\hline Pathological GERD & $4.4(1.2-15.4)$ & $3.9(1.2-12.6)$ & $12.8(3.6-22.4)$ \\
Inconclusive GERD $\leq 80$ & $4.0(0.8-14.2)$ & $4.3(1.1-17.9)$ & $2.7(0.2-16.1)$ \\
Inconclusive GERD $>80$ & $2.9(0.3-25.4)$ & $4.1(1.4-9.7)$ & $8.5(3.2-15.3)$ \\
RH & $1.2(0.2-5.9)$ & $0.6(0.1-3.4)$ & $3.9(0.9-7.1)$ \\
\hline
\end{tabular}

IEM, ineffective esophageal motility; GERD, gastroesophageal reflux disease; $\mathrm{RH}$, reflux hypersensitivity. 
EGJ morphology; further, both EGJ morphology and EGJ-CI independently predict esophageal reflux burden. ${ }^{15}$ Additionally, esophageal body hypomotility features also were similar between pathologic and inconclusive GERD, with similar high proportions of IEM and fragmented peristalsis. Therefore, based on a similar pattern of EGJ morphology, EGJ tone, and esophageal body hypomotility features, inconclusive GERD with $>80$ reflux episodes is phenotypically similar to pathologic GERD.

Our findings suggest that pathologic GERD and inconclusive GERD with $>80$ reflux episodes share motor abnormalities that may work in synergy with EGJ disruption or dysfunction. In particular, while EGJ disruption or dysfunction is a primary pathophysiologic factor in determining reflux occurrence, esophageal body motor function influences duration of contact of the refluxate with the esophageal mucosa, accounting for delayed bolus transit and reduced esophageal reflux clearance in patients with GERD. ${ }^{17}$ It has been shown that the presence of large breaks in esophageal peristaltic integrity on HRM is associated with significantly prolonged supine reflux clearance, higher acid exposure time, and erosive esophagitis. ${ }^{19}$ Large breaks are often identified in the context of suspected GERD-related chronic cough, the presence of which can be associated with suboptimal benefit from antireflux therapy ${ }^{20,21} \mathrm{It}$ has been recently demonstrated that fragmented and failed swallows are correlated with abnormal reflux burden better than weak swallows. ${ }^{14}$ Finally, disruption of the EGJ and absent contractility on HRM are both associated with lower MNBI values. ${ }^{41}$

It is conceivable to speculate that pathological GERD and inconclusive GERD patients, in particular those with $>80$ refluxes during MII-pH monitoring, share similar mechanisms of reflux occurrence. In these patients, the presence of abnormal number of reflux episodes or of pathologic AET may be related to impaired EGJ function or esophageal peristalsis. It is well known that the degree of the reflux burden depends also on several other factors not evaluated in the present study, ie, the saliva buffer function or the rate and duration of transient LES relaxation. Therefore we think that motor findings, observed at HRM, interplay with other mechanisms in determining the reflux burden.

One may speculate that within the spectrum of symptomatic GERD, esophageal motor function plays a pivotal role in the pathophysiology of pathological GERD and inconclusive GERD patients; in contrast, esophageal visceral sensitivity rather than motor function has the key pathophysiologic role in patients with $\mathrm{RH}$ and $\mathrm{FH}^{42}$

The cutoff $4 \%$ and $6 \%$ of the AET has been proposed to better define patients with or without pathological GERD, given the het- erogeneous data in medical literature reporting the normal values in terms of acid exposure among healthy subjects. ${ }^{4}$ More recently, a publication from an international consortium highlighted that the traditional cutoff of $4.2 \%$ was probably overestimated, and when patients have AET values lower than $6 \%$ we should pay more attention on the diagnosis. ${ }^{43}$ Thus, more data are necessary to confirm the conclusive diagnosis, particularly if surgery is suggested. In keeping, our study suggests that patients with pathological GERD and inconclusive GERD may be similar in terms of HRM pattern, but further data such as the evaluation of other variables (ie, MNBI or post-reflux swallow-induced peristaltic wave [PSPW]) may be helpful in better understanding patients falling in the grey area. Future studies confirming our findings are needed. Moreover, it would be of interest to evaluate, in prospective studies, the outcome to the therapy in this group of inconclusive GERD patients. It is conceivable that all of these information will be helpful in clarifying if the Lyon distinction makes sense.

To our knowledge, this is the first study aimed at evaluating the HRM parameters in patients subdivided according to Lyon consensus. Strengths of the present study are the number of patients included and rigorous selection process. However, some limitations may temper the relevance of our findings. The main limitation relates to the retrospective patient identification and data analysis for the purpose of this multicenter study, despite the fact that data collection was prospectively performed independent of the current study across the 3 sites. Moreover, we could not address further outcome following the performance of these esophageal tests. Additionally, additional test features potentially helpful to corroborate our findings were not evaluated (ie, PSPW analysis, histology, etc). A prospective study, with enrollment to each arm determined by power calculations, would have provided more appropriate patient numbers to show differences between groups. Finally, it is known that MII-pH monitoring has a not negligible day-to-day variability rate and this limits the usefulness of MII-pH in GERD diagnosing. Nevertheless, our findings demonstrate the value of esophageal motor pathophysiology from HRM in the evaluation of patients with esophageal symptoms, wherein motor abnormalities, both at the EGJ and in the esophageal body, support GERD rather than a functional esophageal disorder as the primary mechanism for symptoms.

In summary, our results demonstrate that patients with pathologic GERD and those with inconclusive evidence of reflux disease are characterized by similar HRM parameters. In the clinical setting, our findings support the notion that patients with inconclusive evidence of GERD potentially have true reflux disease. These 
results lead to the conclusion that HRM should be performed and results should be taken into account in the evaluation and management of GERD patients.

\section{Financial support: None.}

Conflicts of interest: Mentore Ribolsi, Arvind Rengarajan, Benjamin Rogers, Marco Della Coletta, Matteo Ghisa, Michele Cicala: no disclosures; Edoardo Savarino: consulting (Abbvie, Allergan, MSD, Takeda, Sofar, and Janssen), and teaching and speaking (Medtronic, Reckitt-Benckiser, Malesci, and Zambon); and C Prakash Gyawali: consulting (Ironwood, Torax, and Quintiles), and teaching and speaking (Medtronic and Diversatek).

Author contributions: Mentore Ribolsi: study concept and design, data analysis, and manuscript preparation; Edoardo Savarino: study design, data interpretation, and manuscript preparation; Arvind Rengarajan, Benjamin Rogers, Marco Della Coletta, and Matteo Ghisa: data collection, data interpretation, and critical review of manuscript; Michele Cicala: data interpretation and critical review of manuscript; and C Prakash Gyawali: study concept and design, data interpretation, manuscript preparation, critical review, and final approval of manuscript.

\section{References}

1. Locke GR 3rd, Talley NJ, Fett SL, Zinsmeister AR, Melton LJ 3rd. Prevalence and clinical spectrum of gastroesophageal reflux: a population-based study in Olmsted County, Minnesota. Gastroenterology 1997;112:1448-1456.

2. El-Serag HB, Sweet S, Winchester CC, Dent J. Update on the epidemiology of gastro-oesophageal reflux disease: a systematic review. Gut 2014;63:871-880.

3. Nebel OT, Fornes MF, Castell DO. Symptomatic gastroesophageal reflux: incidence and precipitating factors. Am J Dig Dis 1976;21:953956.

4. Zagari RM, Fuccio L, Wallander MA, Johansson S, Fiocca R, Casanova S, Farahmand BY, Winchester CC, Roda E, Bazzoli F. Gastro-oesophageal reflux symptoms, oesophagitis and Barrett's oesophagus in the general population: the Loiano-Monghidoro study. Gut 2008;57:13541359.

5. Gyawali CP, Kahrilas PJ, Savarino E, et al. Modern diagnosis of GERD: the Lyon Consensus. Gut 2018;67:1351-1362.

6. Savarino E, Zentilin P, Mastracci L, et al. Microscopic esophagitis distinguishes patients with non-erosive reflux disease from those with functional heartburn. J Gastroenterol 2013;48:473-482.

7. Frazzoni M, de Bortoli N, Frazzoni L, Tolone S, Savarino V, Savarino E. Impedance-pH monitoring for diagnosis of reflux disease: new perspectives. Dig Dis Sci 2017;62:1881-1889.
8. Frazzoni L, Frazzoni M, de Bortoli N, et al. Postreflux swallow-induced peristaltic wave index and nocturnal baseline impedance can link PPIresponsive heartburn to reflux better than acid exposure time. Neurogastroenterol Motil 2017;29:e13116.

9. Savarino E, Bredenoord AJ, Fox M, Pandilfino JE, Roman S, Gyawali CP. Expert consensus document: advances in the physiological assessment and diagnosis of GERD. Nat Rev Gastroenterol Hepatol 2017;14:665-676.

10. Rengarajan A, Savarino E, Della Coletta M, Ghisa M, Patel A, Gyawali CP. Mean nocturnal baseline impedance correlates with symptom outcome when acid exposure time is inconclusive on esophageal reflux monitoring. Clin Gastroenterol Hepatol 2020;18:589-595.

11. Gyawali CP, Roman S, Bredenoord AJ, et al. Classification of esophageal motor findings in gastro-esophageal reflux disease: conclusions from an international consensus group. Neurogastroenterol Motil 2017;29:e13104.

12. Fox MR, Bredenoord AJ. Oesophageal high-resolution manometry: moving from research into clinical practice. Gut 2008;57:405-423.

13. Tolone S, de Cassan C, de Bortoli N, et al. Esophagogastric junction morphology is associated with a positive impedance-pH monitoring in patients with GERD. Neurogastroenterol Motil 2015;27:1175-1182.

14. Rengarajan A, Bolkhir A, Gor P, Wang D, Munigala S, Gyawali CP. Esophagogastric junction and esophageal body contraction metrics on high-resolution manometry predict esophageal acid burden. Neurogastroenterol Motil 2018;30:e13267.

15. Gor P, Li Y, Munigala S, Patel A, Bolkhir A, Gyawali CP. Interrogation of esophagogastric junction barrier function using the esophagogastric junction contractile integral: an observational cohort study. Dis Esophagus 2016;29:820-828.

16. Pandolfino JE, Kim H, Ghosh SK, Clarke JO, Zhang Q, Kahrilas PJ. High-resolution manometry of the EGJ: an analysis of crural diaphragm function in GERD. Am J Gastroenterol 2007;102:1056-1063.

17. Kahrilas PJ, Dodds WJ, Hogan WJ, Kern M, Arndorfer RC, Reece A. Esophageal peristaltic dysfunction in peptic esophagitis. Gastroenterology 1986;91:897-904.

18. Rogers BD, Rengarajan A, Mauro A, et al. Fragmented and failed swallows on esophageal high-resolution manometry associate with abnormal reflux burden better than weak swallows. Neurogastroenterol Motil 2019;32:e13736.

19. Bennett MC, Patel A, Sainani N, Wang D, Sayuk GS, Gyawali CP. Chronic cough is associated with long breaks in esophageal peristaltic integrity on high-resolution manometry. J Neurogastroenterol Motil 2018;24:387-394.

20. Almansa C, Smith JA, Morris J, et al. Weak peristalsis with large breaks in chronic cough: association with poor esophageal clearance. Neurogastroenterol Motil 2015;27:431-442.

21. Ribolsi M, Balestrieri P, Emerenziani S, Guarino MP, Cicala M. Weak peristalsis with large breaks is associated with higher acid exposure and delayed reflux clearance in the supine position in GERD patients. Am J Gastroenterol 2014;109:46-51.

22. Vakil N, van Zanten SV, Kahrilas P, Dent J, Jones R. The Montreal definition and classification of gastroesophageal reflux disease: a global 
evidence-based consensus. Am J Gastroenterol 2006;101:1900-1920.

23. Roman S, Gyawali CP, Savarino E, et al. Ambulatory reflux monitoring for diagnosis of gastro-esophageal reflux disease: update of the Porto consensus and recommendations from an international consensus group. Neurogastroenterol Motil 2017;29:1-15.

24. Kahrilas PJ, Bredenoord AJ, Fox M, et al. The Chicago Classification of esophageal motility disorders, v3.0. Neurogastroenterol Motil 2015;27:160-174.

25. Carlsson R, Dent J, Bolling-Sternevald E, et al. The usefulness of a structured questionnaire in the assessment of symptomatic gastroesophageal reflux disease. Scand J Gastroenterol 1998;33:1023-1029.

26. Shaw MJ, Talley NJ, Beebe TJ, et al. Initial validation of a diagnostic questionnaire for gastroesophageal reflux disease. Am J Gastroenterol 2001;96:52-57.

27. Jones R, Junghard O, Dent J, et al. Development of the GerdQ, a tool for the diagnosis and management of gastro-oesophageal reflux disease in primary care. Aliment Pharmacol Ther 2009;30:1030-1038.

28. Eypasch E, Williams JI, Wood-Dauphinee S, et al. Gastrointestinal quality of life index: development, validation and application of a new instrument. Br J Surg 1995;82:216-222.

29. Bengtsson M, Ohlsson B, Ulander K. Development and psychometric testing of the visual analogue scale for irritable bowel syndrome (VASIBS). BMC Gastroenterol 2007;7:16.

30. Guyatt GH, Townsend M, Berman LB, Keller JL. A comparison of likert and visual analogue scales for measuring change in function. J Chronic Dis 1987;40:1129-1133.

31. Patel A, Sayuk GS, Gyawali CP. Parameters on esophageal pH-impedance monitoring that predict outcomes of patients with gastroesophageal reflux disease. Clin Gastroenterol Hepatol 2015;13:884-891.

32. Frazzoni M, Savarino E, de Bortoli N, et al. Analyses of the post-reflux swallow-induced peristaltic wave index and nocturnal baseline impedance parameters increase the diagnostic yield of impedance-pH monitoring of patients with reflux disease. Clin Gastroenterol Hepatol 2016;14:40-46.

33. Savarino E, de Bortoli N, Bellini M, et al. Practice guidelines on the use of esophageal manometry - A GISMAD-SIGE-AIGO medical position statement. Dig Liver Dis 2016;48:1124-1135.

34. Weusten BL, Roelofs JM, Akkermans LM, Van Berge-Henegouwen GP, Smout AJ. The symptom-association probability: an improved method for symptom analysis of 24-hour esophageal $\mathrm{pH}$ data. Gastroenterology 1994;107:1741-1745.

35. Savarino E, Tutuian R, Zentilin P, et al. Characteristics of reflux episodes and symptom association in patients with erosive esophagitis and nonerosive reflux disease: study using combined impedance-pH off therapy. Am J Gastroenterol 2010;105:1053-1061.

36. Ribolsi M, Emerenziani S, Petitti T, Addarii MC, Balestrieri P, Cicala $M$. Increased frequency and enhanced perception of reflux in non-erosive reflux disease patients non-responders to proton pump inhibitors. Dig Liver Dis 2012;44:549-554.

37. Martinucci I, de Bortoli N, Savarino E, et al. Esophageal baseline impedance levels in patients with pathophysiological characteristics of functional heartburn. Neurogastroenterol Motil 2014;26:546-555.

38. de Bortoli N, Martinucci I, Savarino E, et al. Association between baseline impedance values and response proton pump inhibitors in patients with heartburn. Clin Gastroenterol Hepatol 2015;13:1082-1088, e1.

39. Patel A, Wang D, Sainani N, Sayuk GS, Gyawali CP. Distal mean nocturnal baseline impedance on $\mathrm{pH}$-impedance monitoring predicts reflux burden and symptomatic outcome in gastro-oesophageal reflux disease. Aliment Pharmacol Ther 2016;44:890-898.

40. Martinucci I, Savarino EV, Pandolfino JE, et al. Vigor of peristalsis during multiple rapid swallows is inversely correlated with acid exposure time in patients with NERD. Neurogastroenterol Motil 2016;28:243-250.

41. Ribolsi M, Gyawali CP, Savarino E, et al. Correlation between reflux burden, peristaltic function, and mucosal integrity in GERD patients. Neurogastroenterol Motil 2020;32:e13752.

42. Knowles CH, Aziz Q. Visceral hypersensitivity in non-erosive reflux disease. Gut 2008;57:674-683.

43. Sifrim D, Roman S, Savarino E, et al. Normal values and regional differences in oesophageal impedance-pH metrics: a consensus analysis of impedance-pH studies from around the world. Gut Published Online First: 9 Oct 2020. doi: 10.1136/gutjnl-2020-322627. 